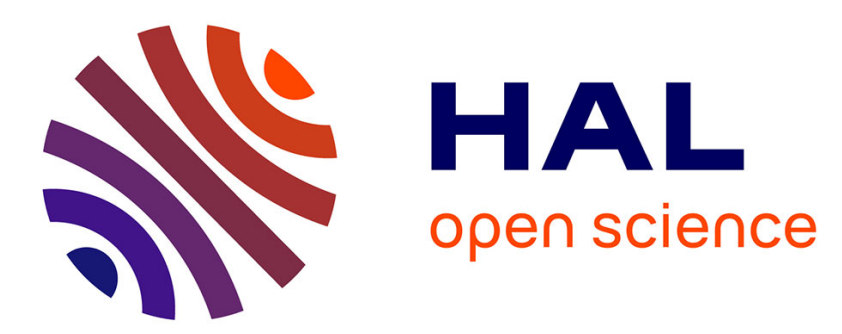

\title{
Couette Rheometry from Differential Approach: Comparative Study and Experimental Application
} Patrice Estellé, Christophe Lanos, Yannick Mélinge, Arnaud Perrot

\section{To cite this version:}

Patrice Estellé, Christophe Lanos, Yannick Mélinge, Arnaud Perrot. Couette Rheometry from Differential Approach: Comparative Study and Experimental Application. THE XV INTERNATIONAL CONGRESS ON RHEOLOGY: The Society of Rheology 80th Annual Meeting, Aug 2008, Monterey, United States. pp.1396-1398, 10.1063/1.2964587 . hal-00672903

\section{HAL Id: hal-00672903 https://hal.science/hal-00672903}

Submitted on 28 Jan 2014

HAL is a multi-disciplinary open access archive for the deposit and dissemination of scientific research documents, whether they are published or not. The documents may come from teaching and research institutions in France or abroad, or from public or private research centers.
L'archive ouverte pluridisciplinaire HAL, est destinée au dépôt et à la diffusion de documents scientifiques de niveau recherche, publiés ou non, émanant des établissements d'enseignement et de recherche français ou étrangers, des laboratoires publics ou privés. 


\title{
Couette Rheometry from Differential Approach: Comparative Study and Experimental Application
}

\author{
Patrice Estellé ${ }^{\mathrm{a}}$, Christophe Lanos ${ }^{\mathrm{a}}$, Yannick Mélinge ${ }^{\mathrm{a}}$, Arnaud Perrot ${ }^{\mathrm{b}}$ \\ ${ }^{a}$ LGCGM Equipe Matériaux et Thermo-Rhéologie - IUT-INSA Rennes, 3 rue du Clos Courtel, BP 90422, \\ Rennes cedex 7, France \\ ${ }^{b}$ Centre de Recherche de St Maudé, Université Bretagne Sud, 56321 Lorient cedex, France
}

\begin{abstract}
This paper presents a recent procedure for recovering the shear flow curve in Couette rheometer from torquerotational velocity data. It is the purpose here to extend the previous works and to compare our predictions in shear flow curve recovery with previous solutions in shear rate determination. With this goal, synthetic and experimental data of yield stress materials in Couette system are presently investigated.
\end{abstract}

PACS: 83

\section{INTRODUCTION}

The Couette viscometer is widely used to evaluate the rheology of liquids and yield stress materials. Converting the experimental data generated by Couette viscometer into material properties in the form of shear stress vs shear rate curve is generally done following several assumptions. It requires prespecification of rheological constitutive model and narrow or wide bob and cup gap approximation from the Couette geometry system used. It is also necessary to calculate shear rate factors which may largely differ following equations used. Recent procedures have been developed to overcome these limitations. Yeow et al. [1] used a regularized least-square approach and Ancey [2] proposed a wavelet-vaguelette decomposition (WVD) as a way of recovering the shear flow curve. These methods are very efficient for complex fluids and yield stress materials. In recent papers, Estellé et al. [3,4] developed a simpler procedure, based on Bingham approximation in shear rate calculation. This procedure was successfully used for computing the shear flow curve of simulated and real fluids in both Couette and vane geometries. It has the added advantage to overcome the problem of a priori knowledge of yield stress value (with viscoplastic fluids) nor the flow regime evaluation within the gap. It is the purpose, here, to extend our previous works and to compare our predictions in shear flow curve recovery with previous methods in shear rate evaluation.

\section{THEORY}

The data of Couette viscometer are put in the form of a shear stress - shear rate relationships from a Bingham approximation in shear rate calculation Estellé et al. [3]. The shear rate of a Bingham fluid is a combination of two expressions following the flow condition in the annulus. It is related to the Couette geometry and set of torque velocity data $(\mathrm{M} ; \Omega)$ from the following equations, respectively when the cylindrical gap is partially sheared (eq. 1) [5] and fully sheared (eq. 2).

$$
\begin{gathered}
\dot{\gamma}=2 M \frac{d \Omega}{d M} \\
\dot{\gamma}=2 \frac{M \frac{d \Omega}{d M}}{\left(1-s^{2}\right)}-\frac{\Omega \cdot-M \cdot \frac{d \Omega}{d M}}{\ln s}
\end{gathered}
$$


Where $s=R_{b} / R_{c}$, respectively the radius of the inner cylinder and the radius of the cup ; $h$ is the height of the inner cylinder.

The central point in this procedure is the use of the maximization of the dissipation of energy to discriminate between the partially sheared gap solution and the fully shear one. This avoids a previous knowledge of the yield stress of the tested fluid. So, from a series of increasing or decreasing rotational velocity $\Omega_{j}$, the shear rate is computed as well as the corresponding shear stress defined as $\tau=\frac{1}{2}\left(\tau_{j}+\tau_{j-1}\right)$, with $\tau_{j}=M_{j} / 2 \pi h R_{b}{ }^{2}$. It should be noted that the derivative $d \Omega / d M$ is simply reduced to $\left(\Omega_{j}-\Omega_{j-1}\right) /\left(M_{j}-M_{j-1}\right)$. This procedure was successfully applied for computing the shear flow curve of simulated and real fluids in Couette viscometer, independently of rheological behaviour and gap size [3]. It was extended to vane geometry for Newtonian silicon oil, CMC solution and Carbopol as yield stress fluid. The results were found to agree well with those obtained using torsional geometry [4]. Synthetic and experimental results of yield stress materials are presently compared to those obtained with the Krieger solutions [6,7] and the modified mid-point (MMP) approximation [8].

\section{APPLICATION AND COMPARATIVE RESULTS}

We have considered here the same synthetic data of Herschel-Bulkley and Casson fluids we used in [3]. As done in [3], the performance of our approach compared to other approximations is estimated by computing the percentage deviation of the calculated shear rate from the true shear rate at the bob which was calculated from the fluid model assumed. In figures 1 and 2, the following shear rate solutions have been considered: the first Krieger solution $\dot{\gamma}=-\Omega / \ln (s)$ for $\mathrm{s} \geq 0.83$ [6], the second Krieger solution $\dot{\gamma}=(2 \Omega / n) /\left(1-s^{2 / n}\right)$ with $n=d \ln \tau_{b} / d \ln \Omega$ and $\mathrm{s} \geq 0.5$ [7], and the MMP approximation $\dot{\gamma}=2 s \Omega /\left(1-s^{2}\right)$ [8].
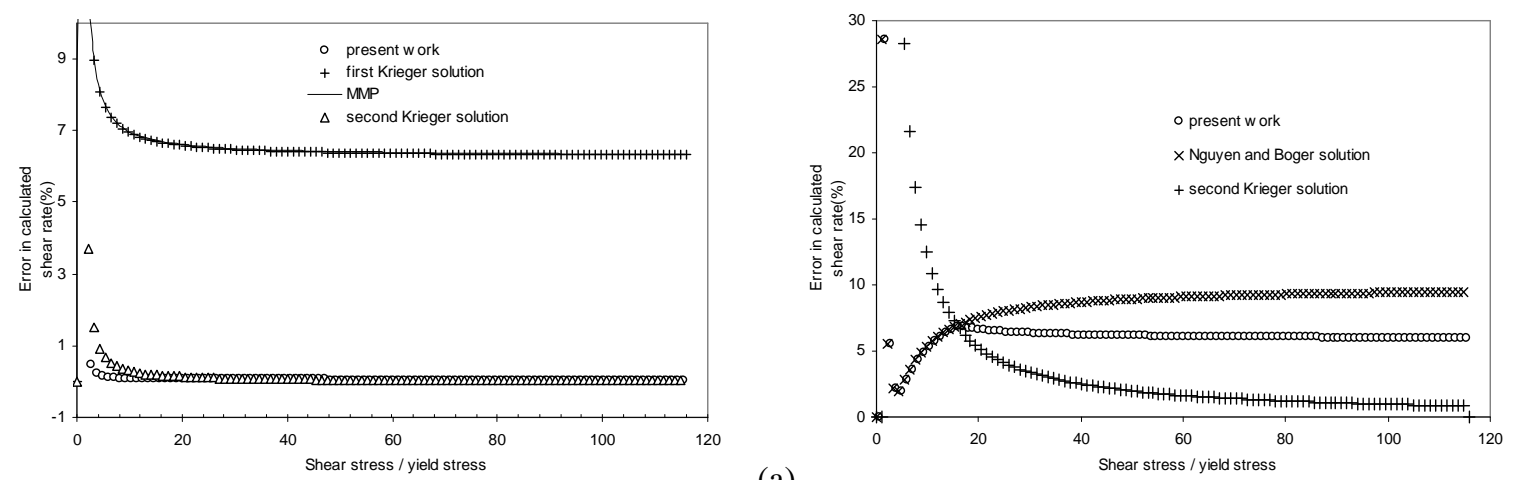

(a)

FIGURE 1. Errors in calculated shear rate of Herschel-Bulkley fluid $\left(\tau_{0}=300 \mathrm{~Pa}, \eta=50 \mathrm{~Pa} . \mathrm{s}^{\mathrm{n}} ; \mathrm{n}=0.6\right)$ using different shear rate approximation techniques for various radius ratios (a) $\mathrm{s}=0.96$; (b) $\mathrm{s}=0.5$.
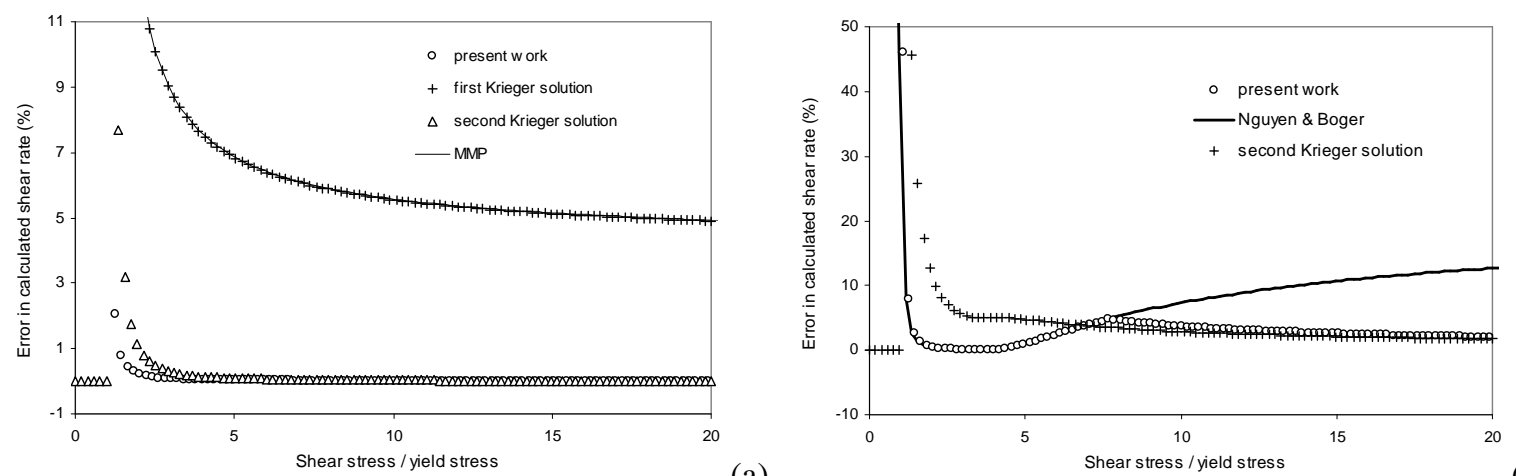

(a)

(b)

FIGURE 2. Errors in calculated shear rate of Casson fluid $\left(\tau_{0}=100 \mathrm{~Pa}, \eta=1 \mathrm{~Pa} . \mathrm{s}\right)$ using different shear rate approximation techniques for various radius ratios (a) $\mathrm{s}=0.96$; (b) $\mathrm{s}=0.5$. 
As a result, the following remarks can be made: with yield stress materials, as the previous comparisons shown, the presently used shear rate calculation overcomes the problem of a priori knowledge of the yield stress value nor the flow regime identification within the gap.

Here, for narrow and moderate gaps, the shear rate values obtained from the Bingham approximation, when the fluid is fully sheared, appear to be comparable and/or better than the Krieger and MMP techniques in the shear rate calculation. It should be noted that the Krieger and the Bingham approximation perform well, while a numerical differentiation technique is used in shear rate calculation, which is not involved with the MMP technique.

In figure 3, we report the shear flow curves of a $0.15 \mathrm{wt} \%$ carbopol gel in both Couette and Vane geometries. Preparation of Carpobol and experimental details are reported in [4]. It is worth noting that the radius ratio $s$ is different following the geometry used. So, it is shown the apparent viscosity prediction of Carbopol in vane and Couette system computed from the procedure described above, as well as the apparent viscosity curve obtained from the Krieger and MMP solutions in Couette geometry.

As can be seen in figure 3(a), the three techniques compare well over the shear rate range investigated in Couette geometry, for a narrow gap. It was checked here that the fluid is always sheared within the gap. It should be noted that this result is in agreement with parallel plate flow curve [4]. In Vane system, the MMP and the first Krieger solutions perform poorly. This can be explained as follow: the fluid is always partially sheared due to the large gap used and rheological behaviour of Carbopol. Moreover, the second Krieger solution and the Bingham approximation compare well under the plug flow condition. This is explained here by the fact that the Krieger solution tends to $\dot{\gamma}=2 \Omega / n$ which is the exact solution for the shear rate under partially shear flow [5].
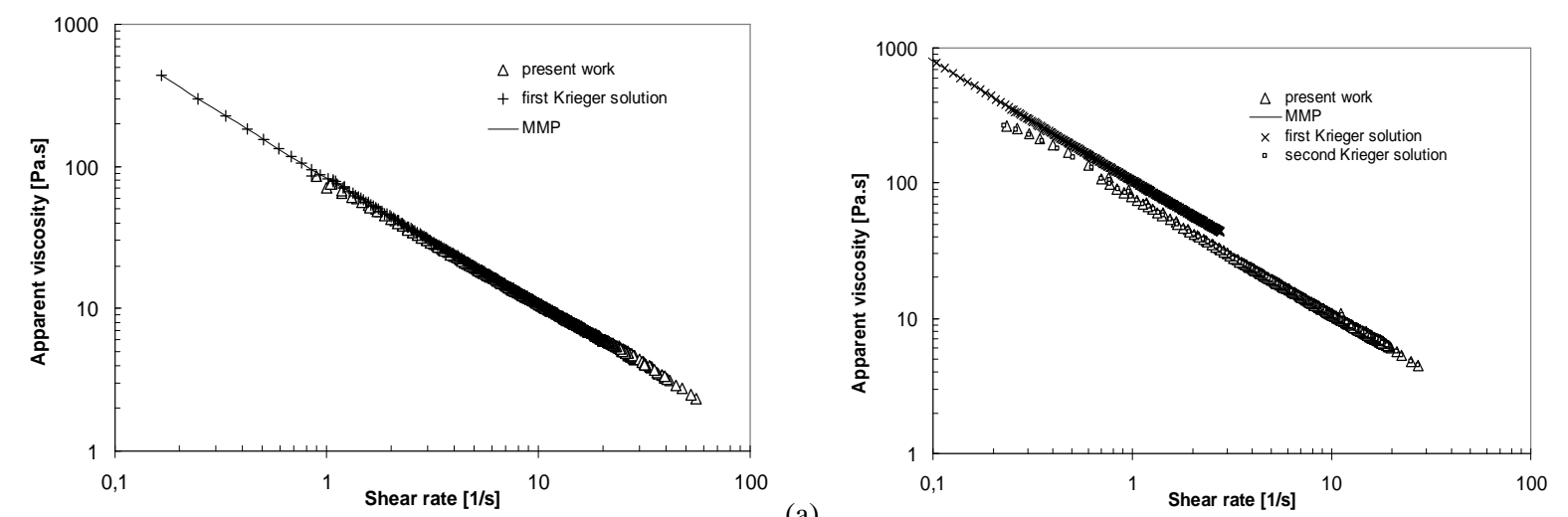

(a)

FIGURE 3. Shear flow curves of Carbopol (a) Couette geometry, $s=0.92$; (b) Vane geometry, $s=0.56$.

\section{ACKNOWLEDGMENTS}

This work is supported by the French National Agency of Research (ANR) under the project Physepat (05-NT05443247).

\section{REFERENCES}

1. Y.L. Yeow et al., J. Rheol. 44, 1335-1351 (2000).

2. C. Ancey, J. Rheol. 49, 441-460 (2005).

3. P. Estellé et al., J. Non-Newt. Fluid Mech. doi:10.1016/j.jnnfm.2008.01.006 (2008).

4. P. Estellé et al., Appl. Rheol., 18:3 34037 (2008).

5. Q.D. Nguyen and D.V. Boger, Rheol. Acta 26, 508-515 (1987).

6. I.M. Krieger and H. Elrod, J. Appl. Phys. 24, 134-136 (1953).

7. T.M.T. Yang and I.M. Krieger, J. Rheol. 22, 413-421 (1978).

8. F.R. de Hoog and R.S. Andersen, Appl. Rheol. 16, 321-328 (2006). 